\title{
Impact of Variable Deterioration Rate of Perishable Food Items on Multi-Echelon Distribution Chains
}

\author{
Dileep M V, Regi Kumar V
}

\begin{abstract}
Customer satisfaction is the backbone of any business entity and supply chain optimization plays a vital role in customer satisfaction efforts. Supply chain inventory control is one of the scientific supply chain optimization methods for determining proper inventory levels at different stages or echelons of the supply chain to meet the requirements of the customers. The intention is to supply right type of material at exact time in appropriate quantities and at competitive rates. Supply chain inventory costs consist of costs to store, track and insure materials. Inventories that mishandled create substantial financial problems for a business, whether the mismanagement results in an inventory accumulation or an inventory shortage. Therefore, an examination of the right quantities to be kept in stock to meet the requirements, the strategic location, storage facilities and recordings of the goods or items should be done systematically such that the desired degree of service can be provided at competitive prices or at minimum ultimate cost. Major objective of inventory control in a multi echelon supply chain is to optimize inventory cost elements like transportation cost, carrying cost, holding cost and all other inventory related costs at all supply chain stages with an elevated service level at the end customer point. The supply chain inventory control becomes tough when the handling material is a perishable one as its deterioration rate is variable rather than constant. This article provides the study results of the deterioration rate of a perishable edible inventory at different selected environmental conditions. The focus of this article is to introduce a mathematical equation for the deterioration rate of the selected perishable inventory which is inevitable for the formulation of inventory models for its supply chain echelons.
\end{abstract}

Keywords: supply chain; deterioration rate; shelf life.

\section{INTRODUCTION}

The global pandemic demands the need of perishable edible goods. These are inevitable in this tough time to sustain life and provide a good immune system to all to resist the illness. This pandemic time demands special attention to the inventory management of such goods because of the demand fluctuation, scarcity of raw materials for production, lack of labour for production, challenges in transportation, storage and distribution due to the wild

Manuscript received on October 11, 2021.

Revised Manuscript received on October 16, 2021.

Manuscript published on October 30, 2021.

* Correspondence Author

Dileep M V*, Lecturer, Department of Mechanical Engineering, Government Polytechnic College, Ezhukone, Kerala (Tamil Nadu), India Email: dileepmvsct@gmail.com

Dr. Regi Kumar V, Professor, Department of Mechanical Engineering, College of Engineering, Trivandrum, Kerala (Tamil Nadu), India. Email: regikumar@cet.ac.in

(C) The Authors. Published by Blue Eyes Intelligence Engineering and Sciences Publication (BEIESP). This is an open access article under the CC BY-NC-ND license (http://creativecommons.org/licenses/by-nc-nd/4.0/) spread of the covid -19 virus. Basically, inventory control of perishable goods or deteriorating inventory is more prevalent because perishable goods like milk, blood, drugs, food and vegetables do deteriorate significantly. Deterioration is defined as decay, damage, wastage, vaporization, obsolescence, pilferage and loss of utility or loss of marginal value of a commodity that results in decreasing utility from the actual one. It is significant to point out that the management of perishable items is intricate as it involves the deterioration of the goods, additional and often complex cost factors such as cost of deterioration, cost of transportation and holding cost. The involvement of cost of deterioration makes the optimization problems related with perishable inventory complicated because the deterioration rates of such items are not constant. It may or may not vary slightly after procurement followed by a rapid deterioration. The transportation cost should also be considered carefully because special enhancements should be presented to counter the deterioration of perishable inventory during its interaction with the logistics systems. Po-Chung Yang and Hui-Ming Weell (2003) developed a multi-lot-size production and inventory model of deteriorating items with constant production, demand rates and constant deterioration rate. The major advantage of the model was that it introduced an optimal policy using the integrated approach which had reduced the total joint cost for the producer and the buyer. The model had limitations that the producer 's cost was higher and it considered a constant deterioration rate for the inventory. Chaman Singh (2011) introduced an integrated supply chain model for the perishable items with fuzzy production rate and fuzzy demand rate. In his mathematical model the optimization of supply chain was by assuming demand rate and production rate as fuzzy numbers. Probability distributions are obtained with historical data. In several cases, especially for new products, the probability will not be easily obtainable because of the lack of historical data and realistic information. Therefore, this work exploited the advantage of fuzzification for the modeling with unknown data. H. Rau, B.C. OuYang (2008) developed an optimal batch size model for integrated production-inventory policy in supply chains. The model was a mathematical one for optimizing the supply chain for a vendor and buyer with an objective to minimize the total cost of the system. This model was based on a single buyer and a single vendor with a single item with constant demand rate. Aditya Shastria et al. (2013) developed a multi-echelon supply chain model for deteriorating items with partial backordering under an Inflationary Environment.

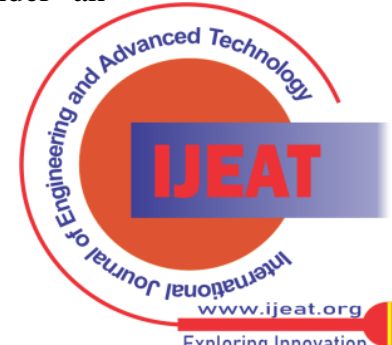


The advantage of this model was that it gave the optimum number of deliveries which minimized the total cost and considered the shortages of the deteriorating inventory and the influence of inflation.

Liang- Hsuan Chen, Fu-Sen Kang, (2007) developed Integrated vendor-buyer cooperative inventory models with variant permissible delay in payments. The advantage of this work was that it introduced integrated models with the permissible delay in payments while determining the optimal replenishment time interval and replenishment frequency. Most of the researchers made their works in the perishable goods by assuming constant demand and constant deterioration rates for the perishable goods.

But the demand rate and deterioration rate are not usually constant and it will vary under the influence of external factors.

Almost all edible goods are subjected to variable deterioration and the factors influencing the deterioration are environmental factors like temperature, humidity etc. Ming-Feng Yang and Wei-Chung Tseng (2015) explained a Deteriorating Inventory Model for Chilled Food which depicted the deterioration of a ready to eat food item with respect to temperature.

They had developed the inventory model for the same based on gompertz model following the experimental research efforts of L.C.lao et al. Angela M Gibson et al. (1987) which analysed the effect of sodium chloride and temperature on the rate and extent of growth of Clostridiurn botulinum type A in pasteurized pork slurry. In this they plotted the growth of CIostridiurn hotulinum type A in pork slurry used for making sandwiches with respect to temperature.

The above studies stress the need of considering the effect of temperature and humidity while modelling inventory models for perishable inventory. Therefore, this regime opens a significant research opportunity since the research works conducted under this assumption are comparatively less. This paper aims at the investigation of the deterioration rate of a perishable edible inventory subjected to a set of major environmental parameters which make it perishable.

\section{INVENTORY DETERIORATION IN MULTI ECHELON DISTRIBUTION CHAIN}

In a multi echelon distribution chain the very significant and primary echelon is the one which is associated with the manufacturer. The flow of goods commences from the manufacturer to the subsequent echelons.

Therefore, supply chain management faces a major challenge to begin the optimization process from this echelon by estimating the stock level at this echelon which reduces the total cost of the chain with due considerations on the deterioration rate and demand rate of the inventory. The Figure. 1 shows the inventory model of manufacturer for a perishable inventory having constant deterioration rate. Inventory level increases form zero for the producer at a finite rate $(\mathrm{p}-\mathrm{d})$ and descends at a fixed deterioration rate $\theta$ for a duration 0 to $T_{1}$. At this point the production comes to an end.

Then, the inventory level decreases due to the constant demand rate' d' units per unit time and at a constant deterioration rate for a period of time 0 toT2 at which the inventory level reaches zero again.

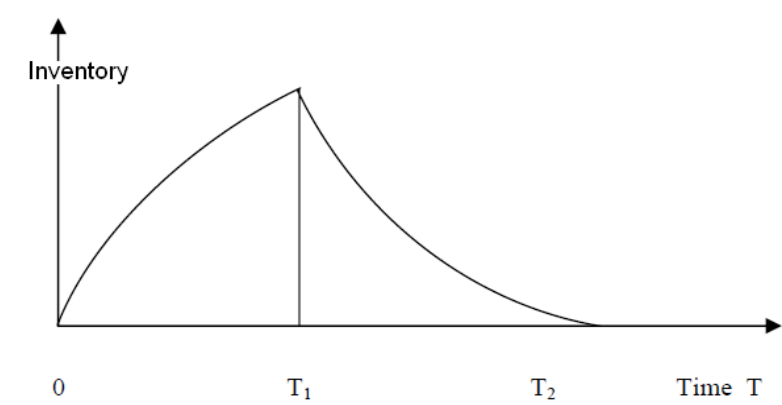

Fig. 1. Manufacturer's Inventory Model

The equations governing the single echelon for the producer for different time durations are as below

I' $\mathrm{p}_{1}\left(\mathrm{t}_{1}\right)=\mathrm{P}-\mathrm{d}-\theta \mathrm{Ip}_{1}(\mathrm{t} 1), 0 \leq \mathrm{t}_{1} \leq \mathrm{T}_{1}$

$\mathrm{I}^{\prime} \mathrm{p}_{2}\left(\mathrm{t}_{2}\right)=\mathrm{P}-\mathrm{d}-\theta \mathrm{Ip}_{2}(\mathrm{t} 2), 0 \leq \mathrm{t}_{2} \leq \mathrm{T}_{2}$

Where $\mathrm{T}=\mathrm{T} 1+\mathrm{T} 2$ subjected to boundary conditions

$\operatorname{Ip}_{1}(0)=0, \operatorname{Ip}_{2}(0)=Q_{p}$ and $\operatorname{Ip}_{2}\left(T_{2}\right)=0$

\section{INVENTORY DETERIORATION OF EDIBLE PERISHABLE GOODS}

The general assumption for the management of inventory is that goods can be stored for a long period. But this assumption is not reasonable for deteriorating inventory because the items which are perishable drop their value with respect to time. This is supposed as the deterioration. The utility of such edible items is represented by their shelf lives. These non-predictable shelf lives of such inventories intensify the intricacy of their management. Also, there are some major factors such as temperature and humidity which result in the variation of their shelf life. The products leave the manufacturers with a certain shelf life, but may have a changed shelf life when they reach ensuing echelons. The shelf lives will certainly vary with respect to products.

Thus, the inventory management systems for the nonperishable items cannot be recommended for the perishable items because of the above reasons. In order to improve the shelf life of perishable goods, prevention of microbe friendly environment and addition of preservatives are the common practices these days. But from a supply chain perspective the spoilage reduction of goods by effectively optimizing stock levels at every echelon is appropriate. The ultimate objective of perishable edible good's supply chain is to supply the precisely needed quantity of goods to the echelons on time when and where they are needed without keeping surplus stock.

\section{EFFECT OF VARIABLE DETERIORATION ON EDIBLE PERISHABLE GOODS}

Most of the recent studies and researches about the supply chain management of perishables assume that their deterioration rates are constant. But real time data from experiments reveal that deterioration rate for perishable goods do not follow a constant pattern. Inventory models for different echelons of the supply chain for these items are entirely different from those of the non-perishable items. 
The inventory models will be so complex for each echelon as the buildup in the system will not actually follow a straight line. The environmental conditions can significantly influence the inventory system, safety stock, maximum inventory level and reorder level. For example, in the manufacturer's Inventory model as shown in the Fig.1 the deterioration rate ' $\theta$ ' is assumed as constant. The inventory buildup pattern and consumption pattern after the time period $T_{1}$ will be different if the deterioration rate of the inventory is variable. Since the deterioration pattern is different, mathematical equations for the deterioration rate should be formulated based on the variability of deterioration rate. As temperature and relative humidity are the major parameters which influence the shelf life of edible goods, the shelf lives of them varies with different combinations of these parameters which makes the analysis lot more complex.

\section{SHELF-LIFE STUDY ON AN EDIBLE PERISHABLE GOOD}

To learn the deterioration of a perishable edible item and obtain an equation for the deterioration rate, an experiment was conducted on it. The items selected for study were homemade bread samples which had no additives in them as preservatives. The bread is selected because it is a regularly consuming item and the deterioration is quite reasonable because the deterioration will not be very fast like other perishable items like milk, meat or blood. The cause of deterioration of the bread is mainly due to the microbes like bacteria, yeast and molds. The mold formation in the bread is the predominant factor which makes the bread inedible compared to others. The most influencing variables for mold formation are environmental parameters like temperature and humidity. There are numerous studies revealing the impact of these parameters on mold formation. Therefore, the study of the pattern of mold formation with respect to the variation in temperature and humidity may throw some light into our selected research endeavors. Such a study can also take us to the behaviour of shelf life for the selected item with respect to the changing atmospheric conditions of several locations. Thus, our focus is on the rate of mold formation in bread for a selected set of variables viz. Temperature and humidity.

\section{METHODOLOGY}

For studying the shelf life, bread samples were kept in an environmental chamber which could simulate the real environmental conditions of strategic locations. The variable parameters taken for shelf-life study were the temperature and relative humidity by assuming the environmental conditions of various conditions such as winter seasons, climatic conditions of high range locations, coastal areas and so on. These parameters were strategically varied by using the environmental chamber to simulate the environmental conditions and the mold formations in the bread as per these environmental conditions were studied. The selected environmental conditions were a) $40 \%$ Relative humidity and temperature $20^{\circ} \mathrm{C}$ b) $50 \%$ relative humidity and temperature $30^{\circ} \mathrm{C}$ c) $60 \%$ relative humidity and temperature $40^{\circ} \mathrm{C}$ and d) $80 \%$ Relative humidity and temperature $45^{\circ} \mathrm{C}$

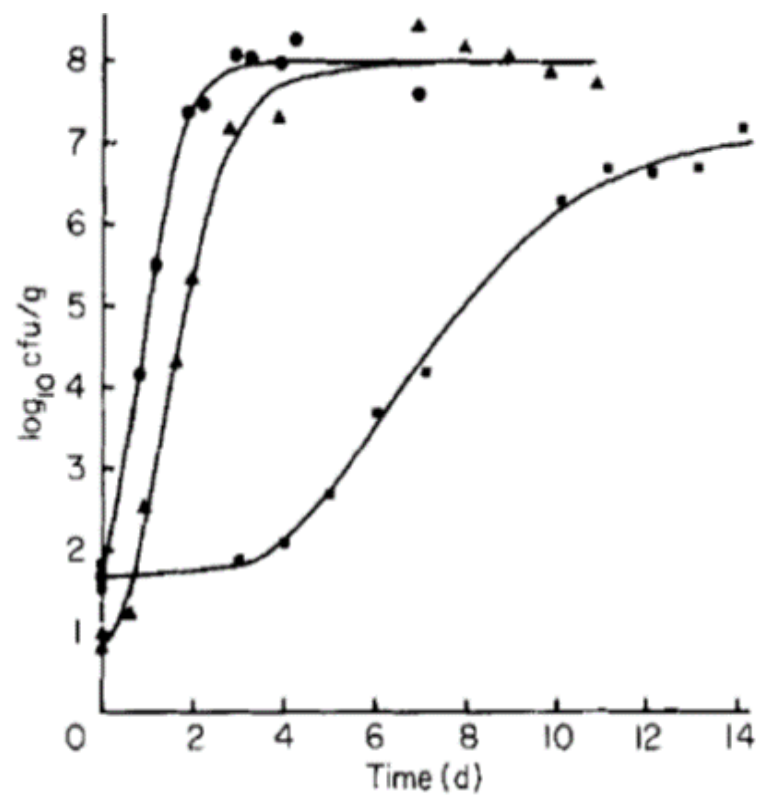

Fig. 2. Gompertz curves

The bread loses edibility when the mold formation exceeds $10 \mathrm{Cfu} / \mathrm{g}$ (colony forming unit per gram) and the duration to have a mold growth of 10Cfu/g can be accounted as the shelf life of the bread for the selected environmental conditions. The curves (Fig.3 to 6) show shelf lives of the bread samples from the experimental observations at the above-mentioned environmental conditions. Such environmental conditions were simulated with the environmental chamber and the mold colony formation units per gram were estimated at regular time intervals. The gompertz model was used to formulate the deterioration rate equation of the bread. The Gompertz curve or Gompertz function is a type of mathematical model for a time series, named after Benjamin Gompertz (1779-1865). It is a sigmoid function which defines growth as being slowest at the start and end of a given time period. The right-hand or forthcoming value asymptote of the function is approached much more gradually by the curve than the left-hand or lower valued asymptote. This is in contrast to the simple logistic function in which both asymptotes are approached by the curve symmetrically. The function was originally intended to describe human mortality, but has been modified to be applied in biology, with regard to detailing populations. These curves consist of four phases which may be compared with the four stages of microbial growth curves: an initial lag phase where no change occurs, followed by a period of accelerating change, a period of decelerating change and finally a stationary period. Fig.2 shows an example for a gompertz curves explaining the effect of temperatures on the growth of CIostridiurn botulinum type A in pork slurry. In this work $\log _{10}$ counts of the number of mold colonies were modelled as a function of time by Gompertz curves for the selected environmental conditions.

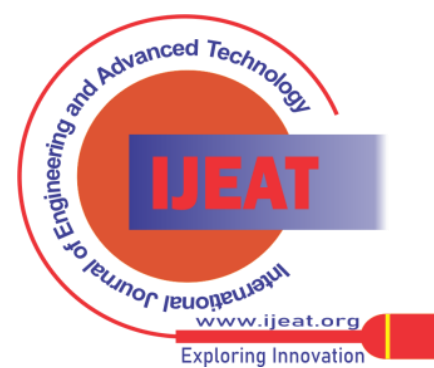




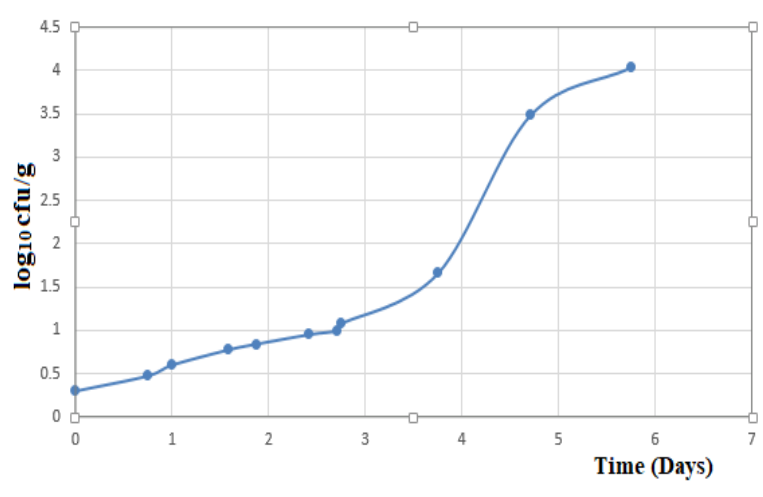

Fig. 3. Shelf life at $40 \% \mathrm{RH}$ and $20^{\circ} \mathrm{C}$

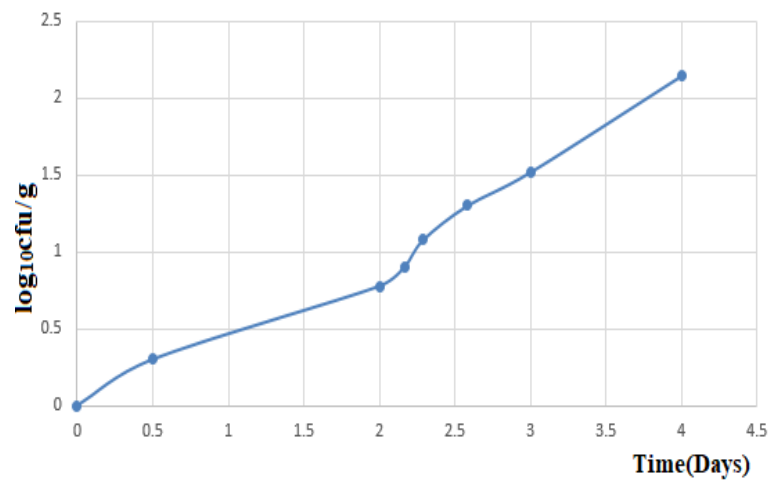

Fig. 4. Shelf life at $50 \% \mathrm{RH}$ and $30^{\circ} \mathrm{C}$

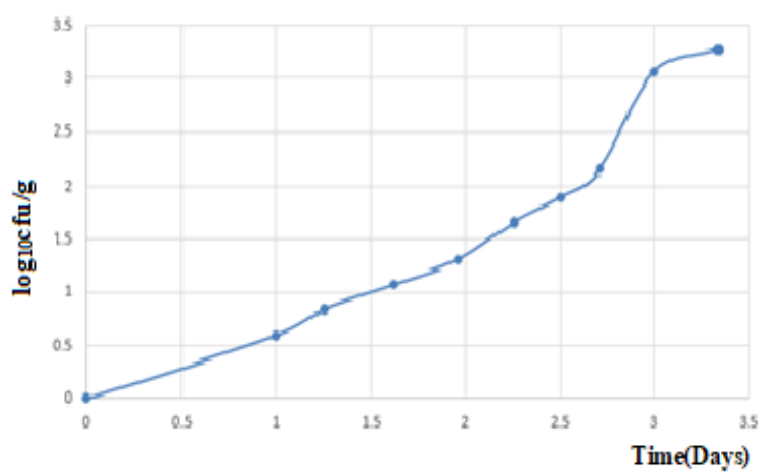

Fig.5.shelf life at $60 \% \mathrm{RH}$ and $40^{\circ} \mathrm{C}$

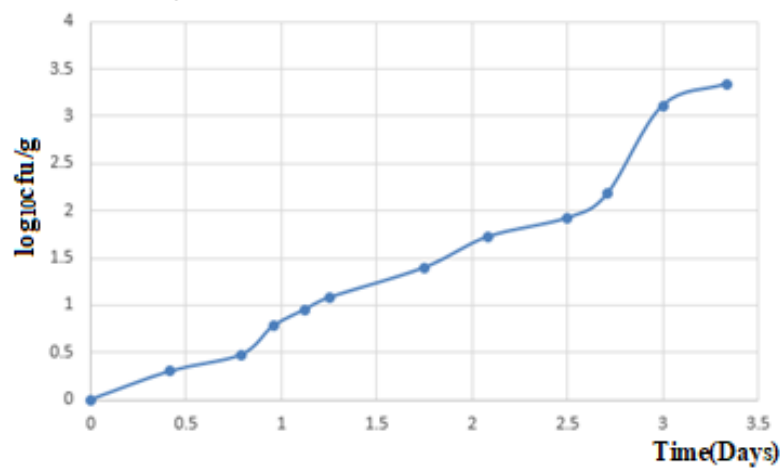

Fig.6.shelf life at $80 \% \mathrm{RH}$ and $45^{\circ} \mathrm{C}$

\section{CURVE EQUATIONS}

In order to obtain the equation for the deterioration rate curves must be fitted to the plots showing the variation of mold growth with respect to the time. The best fit curves for the plots (Fig.3 to 6) which gives $\mathrm{R}^{2}$ values of the order of 0.97 are as given by the equations 1 to 4 respectively

$$
\begin{aligned}
& y=-0.0252 x^{4}+0.2837 x^{3}-0.8649 x^{2}+1.0535 x+0.2274 \\
& y=-0.0371 x^{4}+0.2867 x^{3}-0.6208 x^{2}+0.8057 x+0.006 \\
& y=-0.0683 x^{4}+0.5484 x^{3}-1.1831 x^{2}+1.3933 x-0.0067 \\
& y=0.043 x^{4}-0.1981 x^{3}+0.294 x^{2}+0.6704 x-0.0173
\end{aligned}
$$

where $y$ represents the colony formation units and $x$ the time in days

\section{DETERIORATION RATE}

Equation for deterioration rate for perishable inventory from the above test results was obtained by the gompertz model. The gompertz model is the best suited one to describe the behavior of microbial growth which starts slowly followed by a rapid rate. Therefore, for this approach of problem solving the relative growth rates of the mold were found out for the selected set of temperatures. The relative growth rates (B) are the growth rates of the mold at the times at which the absolute growth rates of the curves 1 to 4 become the maximum. Table 1 shows the variation of $B$ with respect to the temperatures. In order to obtain the equation for the deterioration rate for the selected perishable inventory the Relative growth rates were plotted against the temperature. Thus, an exponential curve was fitted for the plot and the equation of the curve depicts the equation for the deterioration of the perishable inventory.

Table- I: Relative growth rate of mold with Temperature

\begin{tabular}{|c|c|}
\hline Temperature $(\mathrm{t}){ }^{0} \mathrm{C}$ & Relative growth rate(B) \\
\hline 20 & 0.0935 \\
\hline 30 & 1.093 \\
\hline 40 & 1.7 \\
\hline 45 & 2.4 \\
\hline
\end{tabular}

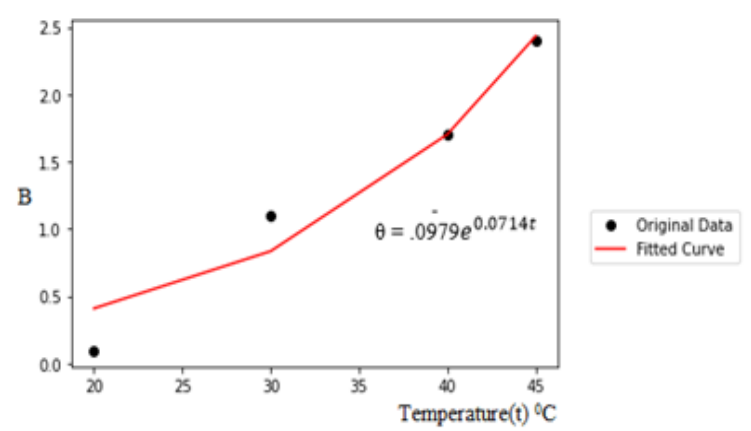

Fig.7.Relative growth rate vs Temperature

Thus, the equation for the deterioration rate of the selected inventory is obtained as $\theta=.0979 e^{0.0714 t}$; where $\mathrm{t}$ is the temperature.

\section{CONCLUSION}

The study discloses that the deterioration rates for perishable edible goods are variable rather than constant. The deterioration rates fluctuate with respect to environmental conditions. 
It can be observed that the deterioration rate increases gradually at the beginning followed by a quickly increasing tendency almost for all the samples tested at different environmental conditions. For the analyzed perishable inventory, the useful shelf life is the time exactly taken for the formation of 10colony formation units of the mold /gram. The flexible deterioration rate is very much important in the optimization of the stock levels to be maintained at various echelons of a distribution chain. The adoption of gompertz analysis to find out the deterioration rate equation for the selected perishable edible inventory elicit a productive output which can contribute to the mathematical modeling of the inventory models for different echelons of a distribution chain and their optimization with a view to bring down the total cost associated with the chain. Though the samples were tested with temperature and humidity, the focus is on rate of deterioration with respect to temperature. This methodology can also be expanded to learn the variation of shelf life by allowing one parameter to remain constant and the other to vary. This methodology may also be useful for the investigation of the shelf lives for an array of similar kinds of perishable goods. The advantage of this study is that it can portray the real behavior of perishable inventory when it is subjected to a set of different climatic conditions and can provide realistic data regarding the shelf life and deterioration rate which increases the accuracy of subsequent efforts to design the inventory models based on variable deterioration rates. But this method is time consuming and challenging. It requires costly equipments, precise methods to collect data, service of micro biological experts and so on.

\section{REFERENCES}

1. Po-Chung Yang, Hui-Ming Wee, "An integrated multi-lot-size production inventory model for deteriorating item", Computers \& Operations Research 30 ,2003, pp.671-682

2. Chamansingh, "An integrated supply chain model for the perishable items with fuzzy production rate and fuzzy demand rate", Yugoslav Journal of Operations Research 21 ,2011, pp.47-64

3. H. Rau, B.C. OuYang, "An optimal batch size for integrated production-inventory policy in a supply chain", European Journal of Operational Research 185 ,2008, pp. 619-634

4. AdityaShastria, S.R. Singh, DharmendraYadav, Shalley Gupta, "Multi-Echelon Supply Chain Management for deteriorating items with Partial Backordering under Inflationary Environment" ProcediaTechnology10,2013, pp.320-329

5. Liang-HsuanChen, Fu-SenKang, "Integrated vendor-buyer cooperative inventory models with variant permissible delay in payments", European Journal of Operational Research 183, 2007, pp.658-673

6. Jian Li, T.C. Edwin Cheng, Shouyang Wang, "Analysis of postponement strategy for perishable items by EOQ-based models", International journal of production economics 107,2007, pp.31-38

7. Mohammad Rahdar, Ali S. Nookabadi, "Coordination mechanism for a deteriorating item in a two-level supply chain system", Applied Mathematical Modelling 38 ,2014,pp.2884-2900

8. Liang-Hsuan Chen, Fu-SenKang, "Integrated inventory models considering permissible delay in payment and variant pricing strategy", Applied Mathematical Modelling, 34,2010, pp.36-46

9. ChamanSingh, S.R.Singh, "Integrated Supply Chain Model for Perishable Items with Trade Credit Policy under Imprecise Environment", International Journal of Computer Applications, 48,2012, pp.36-40

10. A. NagoorGani,G. Sabarinathan,Optimal Policy for Vendor-Buyer Integrated InventoryModel within Just In Time in Fuzzy Environment,International journal of fuzzy Mathematical Archive 2(2013),pp.26-35

11. R. Kalaiarasi,W.Ritha,Optimisation of fuzzy Integrated two stage vendor-buyer Inventory System, International Journal of Mathematical Sciences and Applications 1(2011),pp.659-670

12. Derrien.R.Jansen, ArjenvanWeert , AdrieJ.M.Beulens RuudB.M.Huirne , Simulation model of multi compartment distribution in the catering Supply chain, European Journal of Operational Research,133(2001),pp.210-224

13. Sameer Kumar, AnvarNigmatullin, A system dynamics analysis of food supply chains - Case study with non-perishable products, Simulation Modelling Practice and Theory 19 (2011), pp. 2151-2168

4. Rob A.C.M. Broekmeulen, KarelH.vanDonselaar, A heuristic to shable inventory with batch ordering, positive lead-times, and time-varying demand, Computers\& Operations Research 36 (2009) pp.3013- 3018

15. YongruiDuan, JiazhenHuo, Yanxia Zhang, Jianjun Zhang, Two level supply chain coordination with delay in payments for fixed life time products, Computers\& Industrial Engineering 63 (2012), pp.456-463

16. Kyu Hun Hahn, Hark Hwang, SeongWhanShinn,A returns policy for distribution channel coordinationof perishable items, European Journal of Operational Research 152 (2004), pp.770-780

17. PrzemysławIgnaciuk,Dead-time compensation in continuous-review perishable inventory systemswith multiple supply alternatives,Journal of Process Control 22 (2012),pp.915-924

18. KanchanaKanchanasuntorn, AnularkTechanitisawad,An approximate periodic model for fixed-life perishableproducts in a two-echelon inventory-distribution system,InternationalJournal of Production Economics 100 (2006),pp.101-115

19. JunxiuJia, QiyingHu,Dynamic ordering and pricing for a perishable goods supply chain,Computers\& Industrial Engineering 60 (2011),pp. 302-309

20. Amir H. Masoumi, Min Yu, Anna Nagurney,A supply chain generalized network oligopoly model forpharmaceuticals under brand differentiation and perishability,Transportation Research Part E 48 (2012),pp.762-780

21. Angela.M. Gibson, N. Bratchell\& T.A. Roberts, The effect of sodium chloride and temperature on the rate and extent of growth of Clostridium botulinum type A in pasteurized pork slurry, Journal of Applied Bacteriology 62 (1987), pp. 479- 490

L.C. Iao, H.I. Hsiao, M.F. Yang,Temperature Monitoring for Quality Ready-to-eat Food in Taiwan, No 164772, 2013 International European February 18-22, 2013, Innsbruck-Igls, Austria, Internationa European Forum on System Dynamics and Innovation in Food Networks.

Ming-Feng Yang andWei-Chung Tseng, Deteriorating Inventory Model for Chilled Food, Mathematical Problems in Engineering (2015), pp.1-10

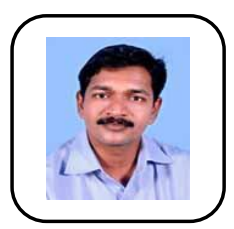

Dileep. M. V. V is a Lecturer in Mechanical Engineering, Government Polytechnic College Ezhukone, Kerala, India. He has earned his MTech in Industrial Engineering from University of Kerala. He is a $\mathrm{PhD}$ scholar at college of Engineering, Trivandrum, Kerala, India. He has got ten years of teaching experience in reputed engineering colleges and three years of experience in Polytechnic colleges. He teaches Industrial Engineering and Supply chain management related subjects and wishes to focus on researches in the same area.

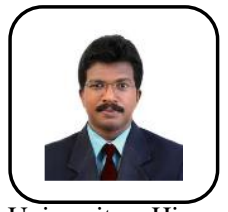

Dr. Regi Kumar V. is a Professor in Mechanical Engineering, College of Engineering Trivandrum, Kerala, India. He has obtained his MTech. in Industrial Engineering and $\mathrm{PhD}$ in Industrial Engineering and Management from University of Kerala and MBA from Indira Gandhi National Open areas of interest include Supply Chain \& Logistics Management, Financial Management, Ergonomic and Inventory Control. He is an active researcher in different areas Industrial Engineering \& Management and published more than hundred papers. He has more than seven years of industrial experience and twentyone years of teaching experience. He engaged as Board of Studies Member, Question Paper setter and PhD adjudicator for various Universities. 